\title{
Eficiencia de la selección en líneas de pimiento (Capsicum annuum), provenientes de cuatro sub-poblaciones, en caracteres de interés productivo
}

\author{
Yaritza Rodríguez, Tomás Depestre y Olimpia Gómez \\ Instituto de Investigaciones Hortícolas Liliana Dimitrova, Carretera Quivicán-Bejucal, km 331/2, \\ Quivicán, La Habana, Cuba. CP 33500.
}

\begin{abstract}
Y. Rodríguez, T. Depestre, and O. Gómez. 2008. Efficiency of selection in pepper lines (Capsicum annuum), from four sub-populations, in characters of productive interest. Cien. Inv. Agr. 35(1):37-49. In Cuba, there is a necessity for pepper lines (Capsicum annum L.) that are well adapted and have multiple resistances to the main viral diseases of big fruits. These cultivars should be used as progenitors in obtaining F1 hybrids with higher quality phenotypes that are more commercially competitive. Therefore, the objective of this work was to characterize the efficiency of the selection in pepper lines derived from four sub-populations. Genetic and statistical parameters were studied to optimize selection in a group of 27 lines, cultivated in a Red Ferralitic soil. Viral resistance was found for Cucumber mosaic virus (CMV) (subpopulation LIRAC), Tobacco etch virus (TEV) (sub-population LIRAE), Potato virus Y (PVY) (sub-population LIRAP) and Tobacco mosaic virus (TMV) (sub-population LIRAV). The virus identification was performed previously in the INRA-Monfavet, France. These results suggest that existent genetic resources of $C$. annuum in Cuba permit the development of multiple lines of resistance, adapted to the local climatic conditions and commercially acceptable productive values in pepper.
\end{abstract}

Key words: Hybrid $\mathrm{F}_{1}$, multiple resistance, pepper.

\section{Introducción}

El pimiento (Capsicum annuum L.) es una hortaliza autógama, originaria de América, de la familia Solanaceae. En los trabajos de mejoramiento genético de esta especie, la selección genealógica ha sido el método más frecuentemente empleado, ya que permite utilizar eficientemente la variabilidad creada.

Dentro del programa de desarrollo agrícola de Cuba, el cultivo del pimiento debería ocupar un lugar destacado en la producción hortícola por su demanda en la población. Actualmente, la producción es de $92000 \mathrm{t}$ anuales, obtenidas en $9.000 \mathrm{ha}$, con rendimientos de $10.2 \mathrm{t}^{\mathrm{h}} \mathrm{ha}^{-1}$ (Anónimo, 2005).

Recibido 09 de abril 2007. Aceptado 19 de diciembre 2007.

'Dirigir correspondencia a Y. Rodríguez: yaritzadana@yahoo.com
La productividad del pimiento se ve disminuida por varias enfermedades virales que causan pérdidas económicas considerables. Algunas de estas enfermedades prevalecen en determinadas regiones, siendo el virus del grabado del tabaco (TEV), virus del moteado suave del pimiento (PepMoV), virus del mosaico del tabaco (TMV), virus Y de la papa (PVY) y virus del mosaico del pepino (CMV), los virus más importantes del pimiento en Cuba. Por lo tanto, la búsqueda de resistencia a estas virosis ha sido prioritaria en los programas de mejora del pimiento (Depestre, 1999).

En Cuba, se hace necesaria una creación varietal sistemática y competitiva para lograr nuevos cultivares que satisfagan los diferentes propósitos comerciales. Estos cultivares deben presentar alto potencial de rendimiento, buena adaptación climática y resistencia a las principales enfermedades de este cultivo. Por este motivo, este trabajo tuvo por objetivo 
caracterizar productivamente (largo y ancho del fruto, número de frutos por planta, peso promedio del fruto y rendimiento por planta) un grupo de sub-poblaciones de pimiento para establecer la eficiencia de la selección.

\section{Materiales y métodos}

\section{Lugar y condiciones de cultivo}

El presente trabajo se realizó en el Instituto de Investigaciones Hortícolas Liliana Dimitrova, Ministerio de la Agricultura (2252' de longitud Norte y 82'23' de longitud Oeste), en el Municipio de Quivicán, provincia La Habana, a 11 m.s.n.m. (IIHLD, 1997).

La siembra del material vegetal se realizó por el método de cepellón, las bandejas se colocaron para su germinación en invernadero, con malla anti mosquita blanca (Bemisia spp.) (Casanova et al., 1999). El transplante se efectúo en octubrediciembre (2003-2005), período óptimo de plantación, en un suelo Ferralítico Rojo Típico a distancia de $0,90 \mathrm{~m} \times 0,30 \mathrm{~m}$ (IIHLD, 1997). Durante el cultivo, se efectuaron las labores establecidas en el instructivo técnico, excepto que no se usó insecticidas para el control de áfidos (IIHLD, 2000; 1999; MINAG, 1984).

\section{Material vegetal estudiado}

Se evaluaron 27 líneas de pimiento, en los ciclos $\mathrm{C}_{7}$ y $\mathrm{C}_{8}$, caracterizadas por presentar baja incidencia y severidad a los virus TMV, PVY, TEV y CMV en los primeros ciclos de selección (C0-C6) en las diferentes sub-poblaciones estudiadas. Cada sub-población se denominó según la resistencia a los virus mencionados (LIRAC- CMV; LIRAE-TEV; LIRAP-PVY; LIRAV-TMV (Rodríguez et al., 2007).

La selección genealógica fue el método utilizado en este trabajo. Se seleccionó un grupo de líneas en el campo con resistencia comprobada a los diferentes virus. Se realizaron los cruzamientos y se crearon las sub-poblaciones. Las líneas de cada sub-población se sembraron individualmente en el campo y la selección se realizó de acuerdo con las resistencias mostradas bajo condiciones de infección natural. Posteriormente fueron autofecundadas para lograr la homocigosis de las mismas y se les realizó una prueba de resistencia en condiciones controladas de laboratorio. Las plantas genéticamente resistentes se volvieron a sembrar en condiciones protegidas, autofecundándose las mismas y las semillas fueron sembradas nuevamente en el campo para cumplir el próximo ciclo.

\section{Parámetros evaluados}

Se evaluaron los siguientes caracteres agronómicos: 1. Número de frutos por planta. 2. Peso promedio del fruto, determinado por tres frutos maduros (rojo) por planta. 3. Rendimiento por planta, medido como el número de frutos por planta por el peso promedio del fruto. 4. Largo promedio de tres frutos. 5. Ancho, promedio de tres frutos. 6. Días entre el trasplante y plena floración. 7. Posición de la primera flor, según la rama en que aparece la flor $(1=$ primera rama, $2=$ segunda rama y $3=$ tercera). 8.Densidaddel follaje, clasificándolocomopoco, moderado o muy denso lo que respectivamente equivalió al 25, 50 y $100 \%$ del follaje potencial de la planta. 9. Longitud del tallo principal, medido desde las hojas cotiledonales hasta la primera bifurcación. 10. Número de hojas en el tallo principal. 11. Longitud de los entrenudos, relación entre el largo del tallo y el número de hojas. 12. Nivel de infección viral, expresado como sintomatología general de la planta según la escala de 0 a 3 , donde $0=$ planta sana, asintomática, $1=$ presencia de un tenue mosaico, 2 = mosaico nítido y $3=$ mosaico severo (Palloix y Depestre, 1998).

La comprobación de la resistencia a los virus anteriormente mencionados se efectuó en los laboratorios de la Unité de Génetique et d'Amelioration des Fruits et Légumes (INRA, Institute Nationale Reserche Agronomique, Montfavet, Francia). Esta consistió en evaluar la sub-población LIRAT para la resistencia al TMV (patotipo común, $\mathrm{P}_{0}$ ), a 22 y $32^{\circ} \mathrm{C}$, teniendo en cuenta las condiciones de Cuba. En la sub-población LIRAP se buscó resistencia a PVYp(1,2), pues los genes que confieren la resistencia a este patotipo también confieren resistencia a los otros dos virus (A. Palloix, comunicación personal, 1992). La subpoblación LIRAE se evaluó para la resistencia 
a TEV (CAU4), por considerarse el aislado más agresivo en el pimiento en Cuba (Depestre, 2002). En la sub-población LIRAC se buscó, a nivel de plántulas, resistencia a CMV Fulton y $\mathrm{CMV} / \mathrm{N}$; el primer virus provoca mosaico y el segundo necrosis en las hojas.

\section{Diseño y análisis estadísticos}

El experimento fue dispuesto en un diseño de bloques completos al azar con cuatro repeticiones. Para el procesamiento estadístico, primeramente fueron determinados los parámetros de dispersión de la media selección para todos los caracteres (X): desviación estándar (DE) y coeficiente de variación $\left(\mathrm{CV} \%=\left(\mathrm{DE} \cdot \mathrm{X}^{-1}\right) \times 100\right)$ en cada sub-población en ambos ciclos.

Las varianzas genotípicas $\left(\sigma_{\mathrm{g}}^{2}=(\mathrm{CM} 1-\mathrm{CM} 2) \cdot \mathrm{r}^{-1}\right)$ y error $\left(\sigma_{\mathrm{e}}^{2}=\mathrm{CM} 2\right)$ fueron determinadas en ambos ciclos de selección $\left(\mathrm{C}_{7}\right.$ y $\left.\mathrm{C}_{8}\right)$ para los caracteres productivos (número de frutos por planta, peso promedio del fruto y rendimiento por planta) (Becker, 1967). Para ello fue necesario realizar un análisis de varianza de clasificación simple, empleando Stat Graphics Plus 5 (Statistical Graphics Corp., Rokville, EUA, 2000). Los promedios se separaron se acuerdo con Tukey.

La heredabilidad en sentido amplio se calculó para los caracteres productivos (número de frutos por planta, peso promedio del fruto y rendimiento por planta) y se determinó su error estándar según las siguientes ecuaciones (Falconer, 1996; Becker, 1967):

$$
\begin{aligned}
& \sigma^{2}{ }_{\mathrm{E}}=\mathrm{CM}_{\mathrm{E}} \quad(\text { varianza del error); } \\
& \sigma^{2}{ }_{\mathrm{w}}=\mathrm{CM}_{\mathrm{w}}-\mathrm{CM}_{\mathrm{E}} / \mathrm{K} 1 \text { (varianza genotípica); } \\
& \mathrm{h}^{2}{ }_{\mathrm{B}}=\sigma^{2}{ }_{\mathrm{w}} /\left(\sigma^{2}{ }_{\mathrm{w}}+\sigma^{2}\right) ; \\
& \mathrm{ESSh}_{\mathrm{B}}{ }_{\mathrm{B}}=\sqrt{ } 2\left(1-\mathrm{h}^{2}{ }_{\mathrm{B}}\right)^{2}\left[1+(\mathrm{K}-1) \mathrm{h}^{2}{ }_{\mathrm{B}}\right) /(\mathrm{K}(\mathrm{K}-1)(\mathrm{N}-1)),
\end{aligned}
$$

donde $\mathrm{N}$, número de grupos o líneas; $\mathrm{M}$, número de individuos por grupos o líneas; $\mathrm{K} 1=$ número de individuos/línea.

En los resultados se representa como: $\mathrm{h}_{\mathrm{B}}{ }_{\mathrm{B}} \mathrm{ES}$ $\mathrm{h}^{2}{ }_{\mathrm{B}}$.

En cada sub-población, la ganancia genética de la selección se calculó en el ciclo C8 para los caracteres productivos (número de frutos por planta, peso promedio del fruto y rendimiento por planta), mediante la fórmula $\Delta \mathrm{G}=\mathrm{XS}_{8}-\mathrm{XG}_{7}$, $\left(\mathrm{XS}_{8}=\right.$ media de las progenies obtenidas, $\mathrm{XG}_{7}=$ media de la población parental (Hallauer, 1985).

La heradibilidad en sentido estrecho $\left(\mathrm{h}_{\mathrm{B}}^{2}\right)$ fueron determinadas según la ecuación $\mathrm{h}^{2}{ }_{\mathrm{B}}=\left(\mathrm{XS}_{8}-\mathrm{XG}_{7}\right) /\left(\mathrm{XS}_{7}-\mathrm{XG}_{7}\right)^{-1}$, siendo $\mathrm{XS}_{7}$ y $\mathrm{XS}_{8}$, las medias de las líneas seleccionadas en $\mathrm{C}_{7}$ y $\mathrm{C}_{8}$, en cada sub-población y $\mathrm{XG}_{7}$, es la media general de las sub-poblaciones en $\mathrm{C}_{7}$ (Falconer y Mackay, 1996). Los caracteres evaluados fueron el número de frutos por planta, peso promedio del fruto y rendimiento por planta.

Se estudiaron las correlaciones fenotípicas para los caracteres productivos, largo y ancho de los frutos, número de fruto por planta, peso promedio del fruto y rendimiento por planta, los que se determinaron en el último ciclo de selección para medir la intensidad de las asociaciones entre las variables estudiadas. Con este propósito se realizó un análisis de múltiples variables (correlaciones de Pearson), empleando Stat Graphics ( $\mathrm{p}=0,05)$, donde las variables se correlacionaron entre sí.

\section{Resultados y discusión}

De acuerdo con los resultados obtenidos, en todas las sub-poblaciones (LIRAC, LIRAE, LIRAV y LIRAP) hubo un incremento en el número promedio de frutos por planta, peso promedio del fruto, rendimiento promedio por planta y densidad promedio del follaje, al pasar del ciclo de selección $\mathrm{C}_{7}$ al $\mathrm{C}_{8}$ (Cuadro 1). Según los resultados obtenidos, se destacó positivamente el ancho del fruto y el número de hojas en la sub-población LIRAC; largo del fruto, longitud del tallo y número de hojas en la sub-población LIRAE; ancho del fruto y la floración en la sub-población LIRAV; y largo y ancho del fruto, número de hojas y longitud de los entrenudos en la sub-población LIRAP. Al mismo tiempo, mejoró considerablemente en el comportamiento a virosis.

La mayor variabilidad en el ciclo $\mathrm{C}_{7}$, estimada por los CV obtenidos, se obtuvo con relación al peso promedio del fruto en LIRAC. En 
Cuadro 1. Características generales de las sub-poblaciones de pimiento (Capsicum annum) en los ciclos $\mathrm{C}_{7} \mathrm{y}_{8}$. Table 1. General characteristics of pepper (Capsicum annuum) sub-populations in the $C_{7}$ and $C_{8}$ cycles.

\begin{tabular}{|c|c|c|c|c|c|c|c|c|}
\hline \multirow{3}{*}{ Parámetros } & \multicolumn{8}{|c|}{ Sub-poblaciones de pimiento en los ciclos reproductivos $\mathrm{C}_{7}$ y $\mathrm{C}_{8}$} \\
\hline & \multicolumn{2}{|c|}{ LIRAC $^{1}$} & \multicolumn{2}{|c|}{ LIRAE $^{1}$} & \multicolumn{2}{|c|}{ LIRAV $^{1}$} & \multicolumn{2}{|c|}{ LIRAP $^{1}$} \\
\hline & $\mathrm{C} 7$ & $\mathrm{C} 8$ & $\mathrm{C} 7$ & $\mathrm{C} 8$ & $\mathrm{C} 7$ & $\mathrm{C} 8$ & $\mathrm{C} 7$ & $\mathrm{C} 8$ \\
\hline \multicolumn{9}{|l|}{ Frutos } \\
\hline Frutos por planta, no. & $11,4 \pm 2,6$ & $12,1 \pm 2,6$ & $14,4 \pm 2,8$ & $16,5 \pm 2,9$ & $14,4 \pm 2,8$ & $15,2 \pm 3,4$ & $16,8 \pm 2,1$ & $17,7 \pm 1,5$ \\
\hline $\mathrm{CV}, \%$ & 4,97 & 4,97 & 19,37 & 17,76 & 19,56 & 22,11 & 12,31 & 8,98 \\
\hline Peso, g & $72,6 \pm 22,1$ & $80,7 \pm 23,8$ & $68,8 \pm 12,12$ & $73,15 \pm 11,8$ & $81,6 \pm 19,4$ & $100,7 \pm 20,2$ & $51,1 \pm 8,3$ & $69,80 \pm 9,4$ \\
\hline $\mathrm{CV}, \%$ & 42,48 & 45,70 & 17,59 & 16,18 & 23,78 & 20,04 & 16,30 & 13,39 \\
\hline \multicolumn{9}{|l|}{ Rendimiento, } \\
\hline $\begin{array}{l}\text { Kg.pranta } \\
\text { CV, \% }\end{array}$ & $\begin{array}{c}0,81 \pm 0,28 \\
0,53\end{array}$ & $\begin{array}{c}0,97 \pm 0,30 \\
0,57\end{array}$ & $\begin{array}{c}0,98 \pm 0,18 \\
18,36\end{array}$ & $\begin{array}{c}1,19 \pm 0,23 \\
19,32\end{array}$ & $\begin{array}{c}1,12 \pm 0,11 \\
9,82\end{array}$ & $\begin{array}{c}1,4 / \pm 0,1 / \\
11,58\end{array}$ & $\begin{array}{c}0,85 \pm 0,1 \\
8,23\end{array}$ & $\begin{array}{c}1,19 \pm 0,1 \\
7,56\end{array}$ \\
\hline Largo, cm & $8,3 \pm 1,0$ & $7,9 \pm 1,0$ & $8,3 \pm 1,8$ & $9,4 \pm 2,0$ & $9,6 \pm 0,6$ & $9,5 \pm 0,82$ & $7,7 \pm 0,6$ & $8,6 \pm 0,9$ \\
\hline $\mathrm{CV}, \%$ & 1,82 & 1,93 & 21,80 & 21,36 & 6,42 & 8,59 & 6,76 & 10,23 \\
\hline Ancho, $\mathrm{cm}$ & $6,5 \pm 0,9$ & $6,6 \pm 0,9$ & $6,7 \pm 0,4$ & $6,1 \pm 0,6$ & $6,1 \pm 0,6$ & $6,2 \pm 0,5$ & $5,3 \pm 0,3$ & $6,3 \pm 0,4$ \\
\hline $\mathrm{CV}, \%$ & 1,73 & 1,82 & 6,59 & 10,42 & 9,75 & 8,18 & 5,48 & 5,71 \\
\hline \multicolumn{9}{|l|}{ Flor } \\
\hline \multicolumn{9}{|l|}{ Plantación a } \\
\hline $\begin{array}{c}\text { floración, d } \\
\text { CV, \% }\end{array}$ & $\begin{array}{c}97,2 \pm 7,3 \\
14,0\end{array}$ & $\begin{array}{c}92,3 \pm 7,6 \\
14,59\end{array}$ & $\begin{array}{c}98,6 \pm 8,4 \\
8,49\end{array}$ & $\begin{array}{c}93,3 \pm 8,9 \\
9,49\end{array}$ & $\begin{array}{c}86,5 \pm 1,4 \\
1,63\end{array}$ & $\begin{array}{c}87,1 \pm 4,9 \\
5,67\end{array}$ & $\begin{array}{c}93,9 \pm 8,2 \\
8,38\end{array}$ & $\begin{array}{c}91,5 \pm 8,2 \\
8,95\end{array}$ \\
\hline Posición & $2,7 \pm 0,3$ & $2,1 \pm 0,27$ & $2,4 \pm 0,3$ & $1,9 \pm 0,3$ & $2,9 \pm 0,2$ & $2,1 \pm 0,4$ & $2,3 \pm 0,2$ & $2,0 \pm 0,2$ \\
\hline $\mathrm{CV}, \%$ & 5,76 & 0,52 & 10,46 & 16,84 & 5,57 & 17,39 & 8,65 & 9,23 \\
\hline \multicolumn{9}{|l|}{ Follaje } \\
\hline Densidad & $4,4 \pm 0,772$ & $4,7 \pm 0,7$ & $4,1 \pm 08$ & $4,6 \pm 0,9$ & $4,3 \pm 1,0$ & $4,4 \pm 1,1$ & $3,8 \pm 1,2$ & $4,0 \pm 1,1$ \\
\hline $\mathrm{CV}, \%$ & 1,48 & 1,36 & 20,40 & 19,12 & 23,60 & 24,60 & 31,9 & 26,76 \\
\hline Tallo, cm & $17,2 \pm 5,5$ & $15,8 \pm 4,9$ & $8,4 \pm 2,1$ & $13,2 \pm 2,2$ & $12,7 \pm 0,7$ & $12,6 \pm 0,8$ & $13,3 \pm 1,4$ & $13,0 \pm 1,4$ \\
\hline $\mathrm{CV}, \%$ & 10,50 & 9,42 & 25,0 & 17,0 & 5,84 & 6,58 & 10,76 & 10,60 \\
\hline Hojas x tallo, no. & $20,0 \pm 4,3$ & $20,9 \pm 3,9$ & $17,2 \pm 4,9$ & $20,5 \pm 5,2$ & $23,9 \pm 5,1$ & $22,0 \pm 5,5$ & $26,3 \pm 2,4$ & $26,4 \pm 2,6$ \\
\hline $\mathrm{CV}, \%$ & 8,21 & 7,44 & 28,30 & 25,35 & 14,68 & 25,18 & 9,25 & 9,70 \\
\hline Entrenudos, $\mathrm{cm}$ & $5,9 \pm 1,4$ & $1,4 \pm 5,8$ & $4,6 \pm 1,4$ & $4,7 \pm 1,5$ & $4,4 \pm 0,4$ & $4,3 \pm 0,5$ & $4,8 \pm 0,3$ & $4,8 \pm 0,4$ \\
\hline $\mathrm{CV}, \%$ & 2,60 & 2,60 & 30,40 & 31,97 & 8,92 & 12,20 & 5,10 & 7,51 \\
\hline Virosis, 0 a 3 & $2,3 \pm 2,0$ & $1,8 \pm 0,9$ & $1,4 \pm 1,4$ & $1,3 \pm 1,3$ & $1,7 \pm 0,9$ & $1,6 \pm 1,0$ & $2,2 \pm 1,0$ & $2,0 \pm 1,1$ \\
\hline $\mathrm{CV}, \%$ & 3,80 & 1,68 & 1,30 & 0,98 & 54,97 & 58,53 & 46,76 & 53,03 \\
\hline
\end{tabular}

${ }^{1}$ Sub-poblaciones: LIRAV $=$ resistente Tobacco mosaic virus $(\mathrm{TMV})$, LIRAP $=$ resistente a Potato virus $Y(\mathrm{PVY})$, LIRAE $=$ resistente a Tobacco etch virus (TEV) y LIRAC = resistente a Cucumber mosaic virus (CMV). La identificación de los virus se realizó en el INRA (Montfaver, Francia).

${ }^{I}$ Sub-populations: LIRAV = resistant to Tobacco mosaic virus $(T M V)$, LIRAP $=$ resistant to Potato virus Y $(P V Y)$, LIRAE $=$ resistant to Tobacco etch virus (TEV), and LIRAC = resistant to Cucumber mosaic virus (CMV). Virus identification was performed at INRA (Montfaver, Francia).

forma similar, se obtuvo alta variabilidad en el número de hojas y longitud de los entrenudos en LIRAE; peso promedio del fruto y densidad del follaje, tanto en LIRAV como LIRAP (Cuadro 1). Esto permitió la mejora de los mismos caracteres en el ciclo $\mathrm{C}_{8}$. El estimado del CV provee el grado de variación con relación a la media de un carácter dado, y pone de manifiesto la variabilidad presente en el mismo y sus posibilidades de mejora. Por lo tanto, el éxito de un programa de mejoramiento genético depende, de la variabilidad presente en el material manejado y de la heredabilidad del carácter (Antuna Grijalva et al., 2003; García y Watson, 2003; Dudi et al., 1983).

La selección por adaptación a las condiciones tropicales debe considerar las condiciones climáticas imperantes en la región, tales como alta intensidad de energía solar y alta pluviometría (Anaïs, 1978). Por esto, el carácter cobertura del follaje es importante, pues los frutos necesitan protección contra la alta radiación global que puede causar escaldadura y quemadura solar, lo 
que desvaloriza el producto comercial. El largo del tallo es también importante en los trópicos, donde usualmente llueve mucho. Los cultivares que poseen el tallo principal corto tienden a exponer los primeros frutos al contacto con el suelo, favoreciendo el desarrollo de pudriciones fungosas y bacterianas (Pérez, 2003; GómezGuillamón y Cuartero, 1986).

En Cuba, los cultivares de pimiento foráneo, provenientes de clima templado, no reúnen las características fenotípicas necesarias para obtener los mejores resultados comerciales en condiciones tropicales (Muñoz de Con et al., 1977). Esto fundamentó el mejoramiento genético por adaptación a las condiciones tropicales locales. Depestre (2002) consideró la importancia de acelerar los trabajos de estabilización genotípicas en Cuba, con el fin de facilitar materiales más productivos.

Por otra parte, la menor incidencia de virosis en la planta es un factor primordial en el proceso de selección, siendo un carácter buscado en cada ciclo con el propósito de lograr resistencia (Cuadro 1). Esta estrategia ha sido utilizada igualmente en trabajos realizados previamente (Depestre, 2002; Rodríguez et al., 2002; Ruíz et al., 2000).
Análisis de la contribución de la varianza en la selección en las sub-poblaciones

La contribución de la varianza genética fue mayor en el carácter peso promedio del fruto, con valores de 136.05 en LIRAC; 55.25 en LIRAE; 178.13 en LIRAV y 76.53 en LIRAP. La menor contribución se obtuvo para el rendimiento por planta. En cuanto a la varianza del error, el peso del fruto fue el carácter que tuvo mayor contribución, con valores que oscilaron entre 2.52 y 9.15 en las sub-poblaciones de pimiento estudiadas. En el rendimiento, dicha varianza tuvo una menor contribución con 0.009; 0.002; 0.007 y 0.003 en las sub-poblaciones LIRAC, LIRAE, LIRAV y LIRAP, respectivamente (Cuadro 2).

Al analizar la varianza genética, al pasar de un ciclo de selección a otro, se observó una disminución en los caracteres número de frutos por planta y peso del fruto en las sub-poblaciones LIRAC, LIRAE y LIRAV (Cuadro 2). Por el contrario, la varianza del error aumentó en los mismos caracteres. En el caso del rendimiento, la varianza genética disminuyó en LIRAE y LIRAV y LIRAP, pero aumentó la varianza del error. Esto explica la homogeneidad dentro de las familias favorecidas por la selección,

Cuadro 2. Análisis de la contribución de las varianzas $\left(\sigma^{2}\right)$ en la selección de líneas de pimiento (Capsicum annum).

Table 2. Analysis of the contribution of the variances $\left(\sigma^{2}\right)$ in the selection of pepper lines (Capsicum annuum).

\begin{tabular}{|c|c|c|c|c|c|c|c|c|}
\hline \multirow{3}{*}{ Parámetros } & \multicolumn{8}{|c|}{ Sub-poblaciones de pimiento ${ }^{1}$} \\
\hline & \multicolumn{2}{|c|}{ LIRAC } & \multicolumn{2}{|c|}{ LIRAE } & \multicolumn{2}{|c|}{ LIRAV } & \multicolumn{2}{|c|}{ LIRAP } \\
\hline & $\mathrm{C} 7$ & C8 & $\mathrm{C} 7$ & $\mathrm{C} 8$ & $\mathrm{C} 7$ & $\mathrm{C} 8$ & $\mathrm{C} 7$ & C8 \\
\hline \multicolumn{9}{|c|}{ Frutos por planta, no. } \\
\hline$\sigma^{2} \mathrm{~g}$ & 2,19 & 1,69 & 2,86 & 3,00 & 8,87 & 6,27 & 3,32 & 2,12 \\
\hline$\sigma^{2} \mathrm{e}$ & 0,14 & 0,57 & 0,33 & 0,83 & 1,07 & 1,55 & 1,43 & 0,54 \\
\hline \multicolumn{9}{|c|}{ Peso promedio de fruto, $\mathrm{g}$} \\
\hline$\sigma^{2} \mathrm{~g}$ & 136,05 & 155,15 & 55,25 & 50,99 & 178,13 & 342,68 & 76,53 & 96,68 \\
\hline$\sigma^{2} \mathrm{e}$ & 2,52 & 3,23 & 4,65 & 9,15 & 2,85 & 5,13 & 3,88 & 4,63 \\
\hline \multicolumn{9}{|c|}{ 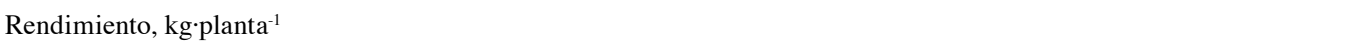 } \\
\hline$\sigma^{2} \mathrm{~g}$ & 0,02 & 0,02 & 0,012 & 0,012 & 0,002 & 0,004 & 0,001 & 0,001 \\
\hline$\sigma^{2} \mathrm{e}$ & 0,009 & 0,005 & 0,002 & 0,018 & 0,007 & 0,029 & 0,003 & 0.006 \\
\hline
\end{tabular}

${ }^{1}$ Sub-poblaciones: LIRAV $=$ resistente Tobacco mosaic virus $(\mathrm{TMV})$, LIRAP $=$ resistente a Potato virus $Y(\mathrm{PVY})$, LIRAE $=$ resistente a Tobacco etch virus (TEV) y LIRAC = resistente a Cucumber mosaic virus (CMV). La identificación de los virus se realizó en el INRA (Montfaver, Francia).

${ }^{I}$ Sub-populations: $L I R A V=$ resistant to Tobacco mosaic virus $(T M V)$, LIRAP $=$ resistant to Potato virus Y $(P V Y)$, LIRAE $=$ resistant to Tobacco etch virus (TEV), and LIRAC = resistant to Cucumber mosaic virus (CMV). Virus identification was performed at INRA (Montfaver, Francia). 
siendo coincidente con resultados previamente obtenidos en otros cultivos (Sahagún, 2007b; Coutiño-Estrada y Vidal-Martínez, 2006; Depestre, 2002; Ahmed, 2000).

\section{Heredabilidad en sentido ancho o grado de determinación genética}

El carácter peso del fruto alcanzó los más altos valores de heredabilidad (cuando se le compara con los otros caracteres estudiados) en: LIRAC (C7 y C8), LIRAE (C7), LIRAV (C7) y LIRAP (C7 y C8). En el carácter rendimiento por planta, la heredabilidad fue alta en todas las sub-poblaciones. Sin embargo, la heredabilidad decreció al pasar de $\mathrm{C} 7$ a C8 en las sub-poblaciones LIRAE $(0,85$ a 0,78 , respectivamente), LIRAV $(0,86$ a 0,64$)$ y $\operatorname{LIRAP}(0,80$ a 0,72$)$ (Cuadro 3).

En relación con el número de frutos por planta, la heredabilidad fue también alta y disminuyó en las sub-poblaciones LIRAC (0,93 a 0,74), LIRAE $(0,89$ a 0,85$)$ y LIRAP $(0,83$ a 0,80$)$ (Cuadro 3$)$. Igualmente, otros autores han encontrado que el carácter peso promedio del fruto alcanza la más alta heredabilidad, posiblemente debido a que es un carácter poco influenciado por el ambiente (Moreno et al., 2006; Sánchez et al., 2006; Pérez, 2003; Depestre, 2002).

La determinación genética mide el grado en que la varianza genotípica es responsable de la variación del fenotipo, y puede variar en distintos caracteres del mismo organismo, para el mismo carácter en organismos distintos e incluso para el mismo carácter en poblaciones distintas del mismo organismo (Asprelli et al., 2001). Se conocen los factores que afectan el estimado de heredabilidad de un carácter, entre ellos son importantes los efectos ambientales, al incrementar el componente de la varianza fenotípica (Ceccarelli, 1989; Blum, 1985). La baja heredabilidad indica un alto efecto ambiental y por consiguiente dificultades en la mejora por selección de un carácter dado. Por el contrario, la heredabilidad alta indica que el carácter es escasamente afectado por el ambiente y siendo su efecto aditivo alto es susceptible de mejorar por selección (Moreno et al., 2006; Gutiérrez del Río et al., 2004; Koinura et al., 1998; Hanson, 1992; Depestre, 1987). Según Ahmed (2000), al trabajar en un programa de mejora del pimiento en Sudán,

Cuadro 3. Heredabilidad en sentido ancho de los caracteres productivos en las sub-poblaciones de pimiento (Capsicum annum) evaluadas en los ciclos $\mathrm{C} 7$ y $\mathrm{C} 8$.

Table 3. Heritability in the broad sense of the production characters in the pepper sub-populations (Capsicum annuum) evaluated in the $C 7$ and $C 8$ cycles.

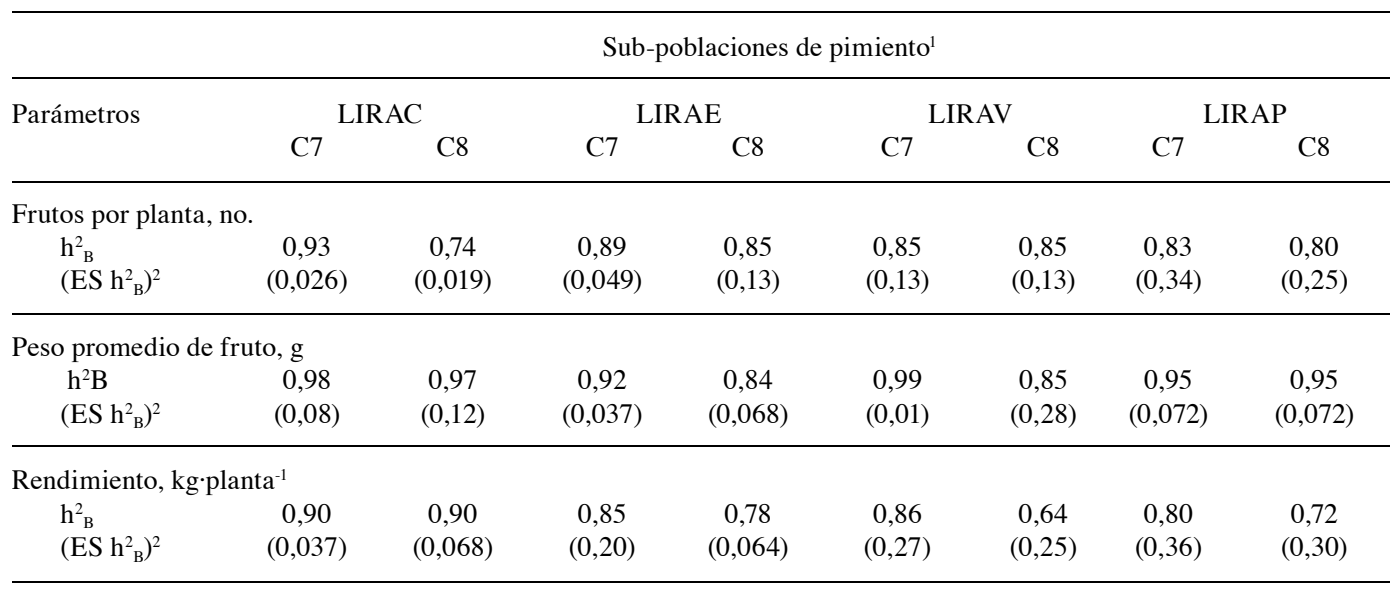

${ }^{1}$ Sub-poblaciones: LIRAV = resistente Tobacco mosaic virus $(\mathrm{TMV})$, LIRAP $=$ resistente a Potato virus $Y(\mathrm{PVY})$, LIRAE $=$ resistente a Tobacco etch virus (TEV) y LIRAC = resistente a Cucumber mosaic virus (CMV). La identificación de los virus se realizó en el INRA (Montfaver, Francia).

${ }^{\prime}$ Sub-populations: $L I R A V=$ resistant to Tobacco mosaic virus $(T M V)$, LIRAP $=$ resistant to Potato virus Y $(P V Y)$, LIRAE $=$ resistant to Tobacco etch virus $(T E V)$, and LIRAC = resistant to Cucumber mosaic virus $(C M V)$. Virus identification was performed at INRA (Montfaver, Francia). C7 and C8 are productive cycles.

${ }^{2}$ ES $h_{B}^{2}=$ error estándar de la heredabilidad. 
la precisión en la selección de los diferentes caracteres, se refleja cuando la heredabilidad en sentido ancho alcanza valores al menos tres veces superiores a su error estándar.

\section{Ganancia genética y heredabilidad en sentido estrecho}

En general, la ganancia genética esperada en los diferentes caracteres estudiados, fue comparable a los cambios que mostraron las medias de cada una de las sub-poblaciones en $\mathrm{C}_{8}$ (Cuadro 4). La mayor ganancia genética se encontró en el carácter peso promedio del fruto, sus valores en las diferentes sub-poblaciones estudiadas fueron de: 8,94 (LIRAC); 12,35 (LIRAE); 35,86 (LIRAV) y 19,66 (LIRAP). Igual ocurrió con este componente productivo en la heredabilidad en sentido estrecho, cuyos valores fueron de: 0,33 (LIRAC); 0,36 (LIRAE); 0,35 (LIRAV) y 0,34 (LIRAP) (Cuadro 4).

La heredabilidad en sentido estrecho indica cuanta de la variación total encontrada en el ensayo se debe a los efectos genéticos aditivos, por lo que la ganancia genética está en función de la heredabilidad y del diferencial de selección se ha establecido previamente (Coutiño-Estrada y Vidal-Martínez, 2006; Ruíz et al., 2000; Hallauer, 1985). La heredabilidad (estima el alcance de la transmisibilidad de un carácter), es importante en la selección de los caracteres objeto de la mejora por selección (Koinume et al. (1998). El haber presentado el peso del fruto un alto coeficiente de variación, así como una alta heredabilidad y ganancia genética, se pudiera deber a efectos genéticos aditivos (Moreno et al., 2006; IIHLD, 2000, 1999; Depestre, 1987). Esto fundamenta los resultados obtenidos en el presente trabajo cuyo objetivo principal fue la mejora de este carácter.

Previamente se ha informado una heredabilidad en sentido estrecho moderada, entre 40-60\%, para los caracteres peso promedio del fruto y rendimiento por planta (Moreno et al., 2006; Rylski, 1983; Stevanovic et al., 1983; Mehra y Meter, 1980). Por otro lado, Gutiérrez del Río et al. (2004) y Singh y Singh (1987) encontraron bajos $(<40 \%)$ estimados de la heredabilidad en sentido estrecho para el número de frutos por planta y el peso del fruto; mientras que para el rendimiento por planta éstos fueron moderados. Los resultados obtenidos en este trabajo fueron bajos en todas las sub-poblaciones para los caracteres productivos estudiados. Esto sugiere que el alcance de la transmisibilidad heredabilidad de un carácter, es importante en la selección de los caracteres objeto de la mejora por selección.

Los estimados de heredabilidad obtenidos demuestran que la selección por productividad en el pimiento es factible, fundamentalmente si se ejecuta en función del peso promedio del fruto, siendo estos resultados, concordantes con estudios previamente realizados (Pérez, 2003; Depestre, 2002; IIHLD, 1999, 2000).

Cuadro 4. Ganancia genética esperada y heredabilidad en sentido estrecho en C8 en los caracteres productivos en todas las sub-poblaciones de pimiento (Capsicum annum).

Table 4. Genetic gain and heritability in the strict sense in the C8 cycle in the production characters in all the pepper sub-populations (Capsicum annuum).

\begin{tabular}{|c|c|c|c|c|c|c|c|c|}
\hline \multirow{3}{*}{ Parámetros } & \multicolumn{8}{|c|}{ Sub-poblaciones de pimiento ${ }^{1}$} \\
\hline & \multicolumn{2}{|c|}{ LIRAC } & \multicolumn{2}{|c|}{ LIRAE } & \multicolumn{2}{|c|}{ LIRAV } & \multicolumn{2}{|c|}{ LIRAP } \\
\hline & $\Delta \mathrm{G}$ & $\mathrm{h}^{2}$ & $\Delta \mathrm{G}$ & $\mathrm{h}^{2}$ & $\Delta \mathrm{G}$ & $\mathrm{h}^{2}$ & $\Delta \mathrm{G}$ & $\mathrm{h}^{2}$ \\
\hline Frutos por planta, no. & 4,45 & 0,29 & 1,92 & 0,12 & 2,64 & 0,16 & 5,13 & 0,15 \\
\hline Peso de fruto, $\mathrm{g}$ & 8,94 & 0,33 & 12,35 & 0,36 & 35,86 & 0,35 & 19,66 & 0,34 \\
\hline Rendimiento, $\mathrm{kg} \cdot$ planta $^{-1}$ & 0,32 & 0,30 & 0,35 & 0,32 & 0,28 & 0,23 & 0,22 & 0,24 \\
\hline
\end{tabular}

${ }^{1}$ Sub-poblaciones: LIRAV = resistente Tobacco mosaic virus $(\mathrm{TMV})$, LIRAP $=$ resistente a Potato virus $Y(\mathrm{PVY})$, LIRAE $=$ resistente a Tobacco etch virus (TEV) y LIRAC = resistente a Cucumber mosaic virus (CMV). La identificación de los virus se realizó en el INRA (Montfaver, Francia). $\triangle \mathrm{G}$, ganancia genética; $\mathrm{h}^{2}$, heredabilidad en sentido estrecho.

${ }^{1}$ Sub-populations: LIRAV = resistant to Tobacco mosaic virus $(T M V)$, LIRAP $=$ resistant to Potato virus Y $(P V Y), L I R A E=$ resistant to Tobacco etch virus $(T E V)$, and LIRAC = resistant to Cucumber mosaic virus $(C M V)$. Virus identification was performed at INRA (Montfaver, Francia). $\Delta G=$ genetic gain; $h^{2}$, heritability in the strict sense. 


\section{Correlaciones fenotípicas}

En la sub-población LIRAC (Cuadro 5) se encontraron correlaciones positivas $y$ significativas entre el rendimiento y el peso del fruto $(\mathrm{r}=0.7877)$, el número de frutos por planta $(\mathrm{r}=0.4595)$, el ancho del fruto $(\mathrm{r}=0.5268)$ y su largo $(\mathrm{r}=0.3486)$. El número de frutos por planta tuvo la influencia positiva del ancho del fruto $(r=0.6426)$, mientras que el peso del fruto la recibió de su largo $(\mathrm{r}=0.7904)$.

En la sub-población LIRAE (Cuadro 5) se encontró una correlación positiva y significativa entre el rendimiento y el número de frutos por planta $(r=0.5452)$, el peso del fruto $(r=0.3353)$ y su largo $(\mathrm{r}=0.4732)$. El número de frutos, también sostuvo una asociación positiva con el largo de los frutos $(r=0.7068)$; mientras que el peso del fruto lo hizo con su ancho $(\mathrm{r}=0.3717)$. Los dos componentes del rendimiento mostraron una correlación negativa y significativa entre si $(\mathrm{r}=-0.3880)$.

En la sub-población LIRAP (Cuadro 5) se encontraron correlaciones altas, positivas y significativas entre el rendimiento con el peso del fruto $(\mathrm{r}=0.7588)$, el largo del fruto $(\mathrm{r}=$ $0.9107)$ y su ancho $(r=0.7467)$. El peso del fruto tuvo, en este caso, la influencia positiva de su ancho $(\mathrm{r}=0.8854)$ y de su largo $(\mathrm{r}=$ 0.7998), al sostener el largo y el ancho del fruto una correlación positiva entre si $(r=0.9085)$. Sin embargo, el peso sostuvo una correlación negativa con el número de frutos $(r=-0.8288)$.

En LIRAV (Cuadro 5) aparecen sólo correlaciones significativas y positiva entre el ancho y el largo del fruto $(r=0.8090)$ y negativa con el número de frutos por planta $(\mathrm{r}=-0.6127)$; además, se encontraron correlaciones negativas y significativas entre el peso promedio del fruto con el número de frutos por planta $(\mathrm{r}=$ $-0.6346)$.

Entre las asociaciones establecidas por los caracteres productivos estudiados en el conjunto de las sub-poblaciones, en la última generación de selección, se destacan las correlaciones positivas y significativas que establecen los caracteres ancho del fruto $(r=0.2046)$, largo del fruto $(r=0.4997)$, número de frutos por planta $(\mathrm{r}=0.5429)$ y peso del fruto $(0.5602)$ con el rendimiento del pimiento (Cuadro 6). En tres de las cuatro sub-poblaciones estudiadas también el rendimiento mantuvo correlaciones positivas significativas con el peso (LIRAC, $\mathrm{r}=$ 0,7877; LIRAP, $r=0,7588$ y LIRAE, $r=0,3353$ ) y con el largo del fruto (LIRAC, $r=0,3486$; LIRAP, $r=0,9107$ y LIRAE, $r=0,4732$ ).

Gutiérrez del Río et al. (2004), Zorzoli et al. (2000), Khaleque et al. (1991) y Suthanthirapandian et al. (1981) informaron que el rendimiento en el pimiento tenía una correlación significativa y positiva con el peso, el ancho del fruto y con el grosor del pericarpio. También estos autores encontraron que la correlación entre el rendimiento del pimiento y el peso del fruto varía en función del tamaño de los frutos de los genotipos estudiados.

En los genotipos de frutos pequeños, cada planta puede desarrollar varios frutos por racimo, en este caso el rendimiento estará influenciado por el carácter número de frutos por planta; por el contrario, en los genotipos de frutos grandes, en la planta se produce aborto de algunas flores a fin de que el resto llegue a la maduración, en cuyo caso es lógico pensar que la producción dependerá del peso del fruto (Rodríguez, 2005; Pérez, 2003; Depestre, 2002). Ello pudiera explicar los resultados encontrados en el análisis de la sub-población LIRAV.

Otros trabajos, han referido correlaciones estrechas entre el rendimiento y el peso del fruto. Así por ejemplo, se ha encontrado que el peso promedio del fruto influyó positivamente en el rendimiento en el $75 \%$ de los ensayos (Moreno et al., 2006; Rodríguez et al., 2002; Asperelli et al., 2001; Berletti y Lanteri, 1985; Gómez-Guillamón, 1982). Por otra parte, Rodríguez (2005) y Pérez (2003) mostraron que el rendimiento estuvo positivamente correlacionado con el número de frutos, número total de flores, largo del fruto y del tallo; mientras que los días a la floración y a la maduración correlacionaron negativamente con el rendimiento.

En el componente número de frutos por planta, influyó positivamente, en el conjunto de las sub-poblaciones, el largo del fruto $(r=$ 
Cuadro 5. Coeficientes de correlación (r) obtenidos entre caracteres productivos estudiados en sub-poblaciones de pimiento (Capsicum annum).

Table 5. Correlation coefficients ( $r$ ) obtained among production characters studied in pepper sub-populations (Capsicum annuum).

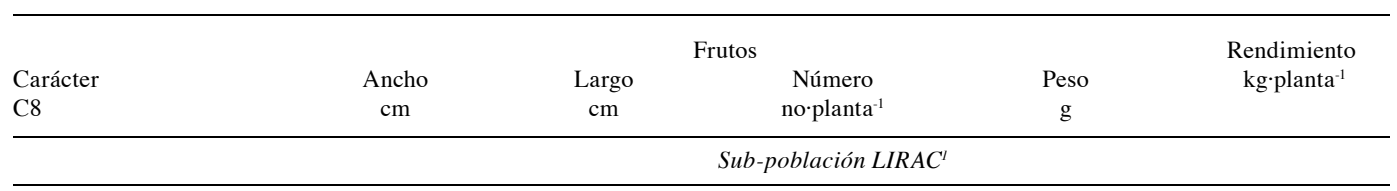

\section{Frutos:}

Ancho, cm

Largo, cm

Número, no·planta ${ }^{-1}$

Peso, g

Rendimiento:

$\mathrm{kg} \cdot$ planta $^{-1}$

$$
\begin{aligned}
& -0,0467 \\
& (0,7397)^{2} \\
& 0,6426 \\
& (<0,0001) \\
& -0,0273 \\
& (0,8460)
\end{aligned}
$$

0,5268

$(0,0001)$

\section{$-0,1945$ \\ $(0,1627)^{2}$ \\ 0,7904}

$(<0,0001)$

0,3486

$(0,0105)$
$-0,1670$

\begin{tabular}{|c|c|c|c|c|c|}
\hline \multicolumn{6}{|l|}{ Frutos: } \\
\hline Ancho, cm & - & & & & \\
\hline \multirow[t]{2}{*}{ Largo, $\mathrm{cm}$} & 0,2699 & & & & \\
\hline & $(0,1114)^{2}$ & - & & & \\
\hline \multirow{2}{*}{ Número, no'planta ${ }^{-1}$} & $-0,0809$ & 0,7068 & & & \\
\hline & $(0,6392)$ & $(<0,0001)^{2}$ & - & & \\
\hline \multirow{2}{*}{ Peso, $\mathrm{g}$} & 0,3717 & $-0,2096$ & $-0,3880$ & & \\
\hline & $(0,0256)$ & $(0,2198)$ & $(0,0194)^{2}$ & - & \\
\hline \multirow{3}{*}{$\begin{array}{l}\text { Rendimiento: } \\
\qquad \mathrm{kg} \cdot \text { planta }^{-1}\end{array}$} & 0,1097 & 0,4732 & 0,5452 & 0,3353 & \\
\hline & $(0,5242)$ & $(0,0456)$ & $(0,0006)$ & $(0,0456)^{2}$ & - \\
\hline & \multicolumn{5}{|c|}{ Sub-población LIRAP } \\
\hline \multicolumn{6}{|l|}{ Frutos: } \\
\hline Ancho, cm & - & & & & \\
\hline \multirow[t]{2}{*}{ Largo, $\mathrm{cm}$} & 0,9085 & & & & \\
\hline & $(0,0018)^{2}$ & - & & & \\
\hline \multirow[t]{2}{*}{ Número, no·planta-1 } & $-0,6738$ & $-0,4010$ & & & \\
\hline & $(0,0669)$ & $(0,3248)^{2}$ & - & & \\
\hline \multirow[t]{2}{*}{ Peso, $g$} & 0,8854 & 0,7998 & $-0,8288$ & & \\
\hline & $(0,0034)$ & $(0,0172)$ & $(0,0110)^{2}$ & - & \\
\hline \multirow{3}{*}{$\begin{array}{l}\text { Rendimiento: } \\
\qquad \mathrm{kg} \cdot \text { planta }^{-1}\end{array}$} & 0,7467 & 0,9107 & $-0,2650$ & 0,7588 & \\
\hline & $(0,0333)$ & $(0,0017)$ & $(0,5258)$ & $(0,0290)^{2}$ & - \\
\hline & \multicolumn{5}{|c|}{ Sub-población LIRAV } \\
\hline \multicolumn{6}{|l|}{ Frutos: } \\
\hline Ancho, $\mathrm{cm}$ & - & & & & \\
\hline \multirow[t]{2}{*}{ Largo, $\mathrm{cm}$} & 0,8090 & & & & \\
\hline & $(0,0014)^{2}$ & - & & & \\
\hline \multirow[t]{2}{*}{ Número, no'planta ${ }^{-1}$} & $-0,6127$ & 0,5392 & & & \\
\hline & $(0,0342)$ & $(0,0705)^{2}$ & - & & \\
\hline \multirow[t]{2}{*}{ Peso, g } & 0,4885 & $-0,3477$ & $-0,6346$ & & \\
\hline & $(0,1071)$ & $(0,2681)$ & $(0,0266)^{2}$ & - & \\
\hline \multicolumn{6}{|l|}{ Rendimiento: } \\
\hline \multirow{2}{*}{$\mathrm{kg} \cdot$ planta $^{-1}$} & 0,2950 & 0,2436 & $-0,1566$ & 0,3561 & \\
\hline & $(0,3519)$ & $(0,4455)$ & $(0,6270)$ & $(0,2559)^{2}$ & - \\
\hline
\end{tabular}

$(0,2321)^{2}$

0,4595

$(0,0005)$

$(<0,0001)^{2}$

${ }^{1}$ Sub-poblaciones: LIRAV = resistente Tobacco mosaic virus $(\mathrm{TMV}), \mathrm{LIRAP}=$ resistente a Potato virus $Y(\mathrm{PVY}), \mathrm{LIRAE}=$ resistente a Tobacco etch virus $(\mathrm{TEV})$ y LIRAC $=$ resistente a Cucumber mosaic virus $(\mathrm{CMV})$. La identificación de los virus se realizó en el INRA (Montfaver, Francia). ${ }^{2}$ Coeficientes de correlación (r) obtenidos por análisis de correlación lineal. En paréntesis se indica la probabilidad obtenida en la respectiva comparación.

${ }^{I}$ Sub-populations: $L I R A V=$ resistant to Tobacco mosaic virus $(T M V)$, LIRAP = resistant to Potato virus Y $(P V Y)$, LIRAE $=$ resistant to Tobacco etch virus $(T E V)$, and LIRAC = resistant to Cucumber mosaic virus (CMV). Virus identification was performed at INRA (Montfaver, Francia). ${ }^{2}$ Correlation coefficients $(r)$ obtained by linear correlation analysis. The estimated probability is indicated in brackets. 
Cuadro 6. Coeficientes de correlación entre caracteres productivos obtenidos en el conjunto de las sub-poblaciones de pimiento (Capsicum annum) estudiadas.

Table 6. Correlation coefficients between productive characters obtained for the overall sub-populations of pepper (Capsicum annum) in this study.

\begin{tabular}{|c|c|c|c|c|c|}
\hline \multirow{2}{*}{$\begin{array}{l}\text { Cáracter } \\
\mathrm{C}_{8}\end{array}$} & \multicolumn{4}{|c|}{ Frutos } & \multirow{2}{*}{$\begin{array}{c}\text { Rendimiento } \\
\mathrm{kg} \cdot \text { planta }^{-1}\end{array}$} \\
\hline & $\begin{array}{l}\text { Ancho } \\
\mathrm{cm}\end{array}$ & $\begin{array}{l}\text { Largo } \\
\mathrm{cm}\end{array}$ & $\begin{array}{l}\text { Peso } \\
\mathrm{g}\end{array}$ & $\begin{array}{l}\text { Número } \\
\text { no·planta }{ }^{-1}\end{array}$ & \\
\hline \multicolumn{6}{|l|}{ Frutos: } \\
\hline Ancho, $\mathrm{cm}$ & - & & & & \\
\hline Largo, cm & $\begin{array}{c}-0.0224 \\
(0.8180)^{1}\end{array}$ & - & & & \\
\hline Peso, g & $\begin{array}{c}0.5279 \\
(<0.0001)\end{array}$ & $\begin{array}{l}-0.0754 \\
(0.4378)^{1}\end{array}$ & - & & \\
\hline $\begin{array}{l}\text { Número, } \\
\text { no·planta }^{-1}\end{array}$ & $\begin{array}{l}-0.2545 \\
(0.008)\end{array}$ & $\begin{array}{c}0.6645 \\
(<0.0001)\end{array}$ & $\begin{array}{c}-0.2888 \\
(<0.0001)^{1}\end{array}$ & - & \\
\hline \multicolumn{6}{|l|}{ Rendimiento: } \\
\hline $\mathrm{g} \cdot$ planta $^{-1}$ & $\begin{array}{c}0.2046 \\
(0.0337)\end{array}$ & $\begin{array}{c}0.4947 \\
(<0.0001)\end{array}$ & $\begin{array}{c}0.5602 \\
(<0.0001)\end{array}$ & $\begin{array}{c}0.5429 \\
(<0.0001)^{1}\end{array}$ & - \\
\hline
\end{tabular}

${ }^{1}$ Coeficientes de correlación (r) obtenidos por análisis de correlación lineal. En paréntesis se indica la probabilidad obtenida en la respectiva comparación.

${ }^{\prime}$ Correlation coefficients $(r)$ obtained by linear correlation analysis. The estimated probability is indicated in brackets.

0,6645), lo que ocurrió también al analizar las correlaciones en las sub-poblaciones LIRAC ( $\mathrm{r}$ $=0,7904)$ y LIRAE $(r=0,7068)$. En el peso del fruto, incidió positivamente el ancho del fruto $(0,5279)$ en el conjunto de las sub-poblaciones, al igual que en LIRAC $(\mathrm{r}=0,6426)$, LIRAP $(\mathrm{r}$ $=0,8854)$ y $\operatorname{LIRAE}(\mathrm{r}=0,3717)$.

Resultados similares han informado en otros trabajos (Pérez, 2003; Ahmed, 2000; BenChaim y Paran, 2000; Shifriss et al., 1992). Los caracteres peso y ancho del fruto y espesor del pericarpio han mostrado altas correlaciones lineales entre si, por lo que se supone la existencia de una dependencia a un mismo sistema genético (Ben-Chaim y Paran, 2000).

Moreno et al. (2006); Zorzoli et al. (2000) y Shifriss et al. (1992) encontraron dominancia parcial para el carácter peso del fruto y recomiendan tener en cuenta el ancho del fruto cuando tratan de incrementar su peso, siempre que el grosor del pericarpio se encuentre constante.

Sin embargo, los dos componentes del rendimiento, el número de frutos $\mathrm{y}$ su peso, sostuvieron una correlación negativa significativa entre si $(r=-0,2888)$ en el conjunto de las sub-poblaciones y en tres de ellas (LIRAE, $r=-0,3880$; LIRAP, $r=-0,8288$ y LIRAV, $r=-0,6346)$. Previamente se han reportado resultados similares (Moreno et al., 2006; Zorzoli et al., 2000; Gómez-Guillamón y Cuartero, 1986; Depestre et al., 1985; Arya y Saini, 1976).

Se ha informado de la existencia de cambios en las correlaciones entre los caracteres estudiados en las poblaciones a través de los ciclos y períodos de selección, los que se atribuye al ambiente (Moreno et al., 2006; Rodríguez, 2005; Gutiérrez del Río et al., 2004; Cramer y Wehner, 1998; De Koeyer y Stuthman, 1998; Hanson, 1992). La selección indirecta, teniendo en cuenta el monitoreo de las correlaciones de importancia halladas, se hace necesaria en la mejora para modular la presión de selección y tratar de eliminar los efectos de caracteres indeseables (Ruíz y Martin, 2000; Koinume et al., 1998).

Sánchez et al. (2006); Rodríguez (2005); Koinume et al. (1998) y Silvetti y Giovanelli (1976) hallaron efectos, tanto aditivos como dominantes, en caracteres cuantitativos estudiados en el pimiento, por lo que plantean como esencial el estudio de los parámetros genéticos y el modo 
de herencia, antes de emprender un programa de mejoramiento en $C$. annuum.

De acuerdo con los resultados obtenidos, es posible concluir que la estrategia basada en el manejo de fuentes de resistencia existentes en los recursos genéticos disponibles es válida para lograr resistencia múltiple, adaptación climática y valores productivos aceptables en pimiento.

\section{Resumen}

En Cuba, existe necesidad de contar con líneas de pimiento (Capsicum annuum L.) con resistencia múltiple a las principales enfermedades virales, de frutos grandes y de buena adaptación. Estos cultivares deberían ser utilizados como progenitores en la obtención de híbridos F1 con mejores cualidades fenotípicas y comercialmente más competitivos. Por lo tanto, este trabajo tuvo por objetivo caracterizar productivamente líneas de pimiento proveniente de cuatro sub-poblaciones para establecer la eficiencia de la selección. Se estudiaron los parámetros genéticos y estadísticos que optimizan la selección para caracterizar un grupo de 27 líneas en conjunto, cultivadas en un suelo Ferralítico Rojo. Se determinó resistencia los virus del mosaico del pepino (CMV) (subpoblación LIRAC), virus del grabado del tabaco (TEV) (sub-población LIRAE), virus Y de la papa (PVY) (Sub-población LIRAP) y virus del mosaico del tabaco (TMV) (Sub-población LIRAV). Estos virus fueron previamente determinados en el INRA-Monfavet, Francia. De acuerdo con los resultados obtenidos, es posible concluir que la estrategia basada en el manejo de fuentes de resistencia a virosis, existentes en los recursos genéticos de $C$. annuum disponibles en Cuba es válida para lograr resistencia múltiple, adaptación climática y valores productivos aceptables en pimiento.

Palabras clave: Híbridos F1, multiresistentes, pimiento.

\section{Literatura citada}

Ahmed, E.A. 2000. A breeding strategy for constructing multiresistant genotypes of sweet pepper adapted for cultivation in the tropics.
PhD Thesis, Universidad of Gezira, Gezira, Sudán. 224 p.

Anäis, G. 1978. Adaptation des varietes maraicheres au climat des Antilles. (Tropical Humide). Centre des Recherches Agronomiques des Antilles et de la Guyane. Petit Bourg, Domaine Duclos, Guadalupe. 5 p.

Anónimo. 2005. Production Yearbook. FAOSTAT, Rome, Italia. Instituto de Investigaciones Hortícola Liliana Dimitrova, Ministerio de la Agricultura, La Habana, Cuba. www faostat. fao.org/site/499/default.aspx. (Consultado: mayo de 2007).

Antuna Grijalva, O., F. Rincón Sánchez, E. Gutiérrez del Río, N.A. Ruiz Torres y L. Bustamante García. 2003. Componentes genéticos de caracteres agronómicos y de la calidad fisiológica de semillas de líneas de maíz. Revista Fitotecnia Mexicana 26:11-17.

Arya, P.A. y S.S. Saini. 1976. Genetic variability and correlation studies in bell peppers. Indian Journal of Agricultural Research 10:223-228.

Asprelli, P., V. Cravero y E. Cointry. 2001. Evaluación de la variabilidad presente en una población de clones de acaucil (Cynara scalymus L.). Revista de Investigaciones de la Facultad de Ciencias Agropecuarias (Zavalla, Santa Fe, Argentina) 5:45-52.

Becker, W.A. 1967. Manual of Procedures in Quantitative Genetics. Second ed. Washington State University, Pullman, Washington. 129 p.

Ben-Chaim, A. y I. Paran. 2000. Genetic analysis of quantitative traits in pepper (Capsicumannuиm). Journal American Society Horticultural Science 125:66-70.

Berlleti, P. y S. Lanteri. 1985. Correlation between several features of pepper fruits. Capsicum Newsletter and Eggplant 4:27.

Blum, A. 1985. Breeding crop varieties for stress environments. Critical Reviews Plant Sciences 2:199-238.

Casanova, A., O. Gómez, H. Cardoza, J.C. Hernández, C. Murquido y M. León. 1999. Guía Técnica para la Producción de Tomate. Instituto de Investigaciones Hortícolas Liliana Dimitrova, Quivicán, La Habana, Cuba. 4 p.

Ceccarelli, S. 1989. Wide adaptation: How Wide? Euphytica 40:197-205.

Coutiño-Estrada, B. y V.A. Vidal-Martínez. 2006. Variance components of corn hybrids evaluated in the USA corn belt. Agrociencia 40:89-98.

Cramer, C.S. y T.C. Wehner. 1998. Fruit yield and yield component means and correlations of four slicing cucumber populations improved through six to ten cycles of recurrent selection. Journal American Society Horticultural Science 123:388-400. 
De Koeyer, D.L. y D.D. Stuthman. 1998. Continue response through seven cycles of recurrent selection for grain yield in oat (Avena sativa L.). Euphytica 104:67-72.

Depestre, T. 1987. Heritability studies on sweet pepper. Capsicum Newsletter and Eggplant 6:43-44.

Depestre, T. 1999. An approach to pepper breeding in Cuba. Capsicum Newsletter 18:16-20.

Depestre, T. 2002. Construcción de multirresistencia a enfermedades virales y adaptación al trópico en genotipos de pimiento (Capsicum annuum L.) y su aplicación. Instituto de Investigaciones Hortícolas Liliana Dimitrova, Ministerio de la Agricultura. Cuba. www.cuba.cu/ciencia/acc/ agrarias 2002_ resumen.htm. (Consultado: marzo de 2007).

Depestre, T., O. Gómez, and J. Espinosa. 1985. Genetic parameters in pepper. Capsicum Newsletter 4:28.

Dudi, B.S., J. Divit y P.S. Pastarp. 1983. Components of variability, heredability and genetic advance studies in tomato (Lycopersicum sculentus, Mill). Haryana Agricultural University Journal of Research 12:135-139.

Falconer, D.S. 1996. Genética cuantitativa. p: 369382. In: D.S Falconer and T.F.C. Mackay (eds.). Introduction to Quantitative Genetics. Fourth ed. Longman Group Ltd., NY, USA. 350 p.

García, M. y C.E. Watson. 2003. Herencia de la resistencia al acame de raíces en maíz dulce (Zea mays L). Revista Científica UDO Agrícola 3:24-33.

Gómez-Guillamón, M.L. 1982. Genética de Caracteres Apreciables a la Mejora del Pimiento (Capsicum annuum L) en el Cultivo de Invernadero. Tesis Doctoral. Editorial Universitario. Málaga, España. 258 p.

Gómez-Guillamón, M.L. y J. Cuartero. 1986. Inheritance of vegetative characters in pepper (Capsicum annuum L.). Agronomie 7:271-277.

Gutiérrez del Río, E., A. Espinoza Banda, A. Palomo Gil, J.J. Lozano García y O. Antuna Grijalva. 2004. Aptitud combinatoria de híbridos de maíz para la comarca lagunera. Revista Fitotecnia Mexicana 27:7-11.

Hallauer, A.R. 1985. Compendium of recurrent selection methods and their application. Critical Reviews Plant Sciences 3:1-33.

Hanson, W.D. 1992. Phenotypic recurrent selection for modified reproductive period in soybean. Crop Science 32:968-972.

IIHLD. 1997. Memorias 25 Aniversarios. Localización, clima y suelos. Instituto de Investigaciones Hortícolas Liliana Dimitrova, Quivicán, La Habana, Cuba. 98 p.

IIHLD. 1999. Plan de medidas recomendadas para el desarrollo integral del tomate y del pimiento. Archivo Instituto de Investigaciones Hortícolas Liliana Dimitrova, Quivicán, La Habana, Cuba. $6 \mathrm{p}$.

IIHLD. 2000. Desarrollo perspectivo de la producción de tomate y pimiento en Cuba. Archivo Instituto de Investigaciones Hortícolas Liliana Dimitrova, Quivicán, La Habana, Cuba. $15 \mathrm{p}$.

Khaleque, M.A., G.N.M. Illias y M. Qaisuddin. 1991. Study of variability and correlation of some chemical characteristics in chilli (Capsicum annuum L), Bangladesh. Journal of Botany 20:37-41.

Koinume, K, F. Ikegaya y E. Ito. 1998. Heterotic effects for root lodging resistance in F1 hybrids among dent flint in bred lines of silage maize. Maydica 43:13-17.

Mehra, C.S. y K.V. Meter. 1980. Genetic divergence in chilli. Indian Journal Agricultural Science 50:477-481.

MINAG. 1984. Instructivo técnico del cultivo del pimiento. La Habana. Dirección Nacional de Cultivos Varios. Ministerio de la Agricultura, Cuba. 29 p.

Moreno, M., A. Peña, J. Sahagún, J.E. Pérez y R. Mora. 2006. Varianza aditiva, heredabilidad y correlaciones en la variedad. M1- Fitotecnia de tomate de cáscara (Physales ixorcarpa Brot). Revista Fitotecnia Mexicana 25:231-237.

Muñoz de Con, L, J.L. Pérez y A. Prats. 1977. Hortalizas mejoradas. Ciencias de la Agricultura 3:39-47.

Palloix, A. y T. Depestre. 1998. LIRA: A virus multirresistant pepper population for tropical conditions. Proceedings of the $\mathrm{X}^{\text {th }}$ EUCARPIA Meeting on Genetics and Breeding of Capsicum and Eggplant. Avignon-Montfavet, France. p. 96-110.

Pérez, R. 2003. Estimación de Parámetros Genéticos para la Tolerancia Sequía en Chile Cora, Capsicum annuum L. Tesis, Doctor en Ciencias en Agrícolas y Forestales. Universidad de la Colima. Tecomán, Colima, México. 133 p.

Rodríguez, J.E.P. 2005. Parámetros genéticos de tomate de cáscara (Physalis ixocarpa) variedad verde de Puebla. Revista Fitotecnia Mexicana 27:7-11.

Rodríguez, Y., T. Depestre y O. Gómez. 2007. Obtención de líneas de pimiento (Capsicum annиum) progenitoras de híbridos F1, resistentes a enfermedades virales, a partir del estudio de cuatro sub-poblaciones. Ciencia e Investigación Agraria 34:237-242.

Rodríguez, Y., E. Rangel, F. Centeno, A. Mendoza y A. Parra, 2002. Virus diseases affecting sweet peppers in Quibor Valley. Proc. of 
the $16^{\text {th }}$ International Pepper Conference. Tampico, Tamaulipas. November 12-14. Quibor (Venezuela). p. 45-50.

Ruiz, M. y Martin, I. 2000. Las variedades autóctonas. Un patrimonio genético que no debemos perder. Cámara Agraria 4:13-14.

Rylski, I. 1983. Effect of high temperature on shape and size of sweet pepper (Capsicum annuum L). Journal American Society Horticultural Science 98:149-152.

Singh, A. y H.N. Singh. 1987. Genetic components for yield and its contributing traits in chilli, Haryana. Journal Horticultural Science 6:155160.

Stevanovic, D., Z. Miladinovic y N. Marinkovic. 1983. Inheritance of some characters of pericarp in pepper. pages 63-70. In: Proceedings of the Meeting of the Capsicum and Eggplant Working Group of the Eucarpia. 4-7July. Instituto de Investigaciones Horticolas Maritza, Plovdiv, Bulgaria.
Sánchez, M.A., J. A. Mejias, C. Villanueva, J. Sahún, A. Muñoz y J.D. Molina. 2006. Estimación de parámetros genéticos en la calabaza pipiana (Cucúrbita arzyrosperma Huber). Revista Fitotecnia Mexicana 29:127-136.

Silvetti, E. y P. Geovanelli. 1976. Diallel análisis of quantitative traits in $C$. annuum $\mathrm{L}$. Genetic Agricultural 30:347-353.

Shifriss, C., M. Pilowsky y J. Zacks. 1992. Resistance to Leveillula taurica (Odiopsis taurica) in Capsicum annuum. Phytoparasitica 20:279-283.

Suthanthirapandian, I.R., M. Elangovan y P. Rengasamy. 1981. Association of metric traits in chilies (C. annuum L.). South Indian Horticulture 29:70-74.

Zorzoli, R., G.R.Pratta y L.A. Picardi. 2000. Variabilidad genética para la vida postcosecha y el peso de los frutos en tomate para familias $\mathrm{F}_{3}$ de un híbrido ínter especifico. Pesq. Agropec. Bras. 35:2423-2427. 